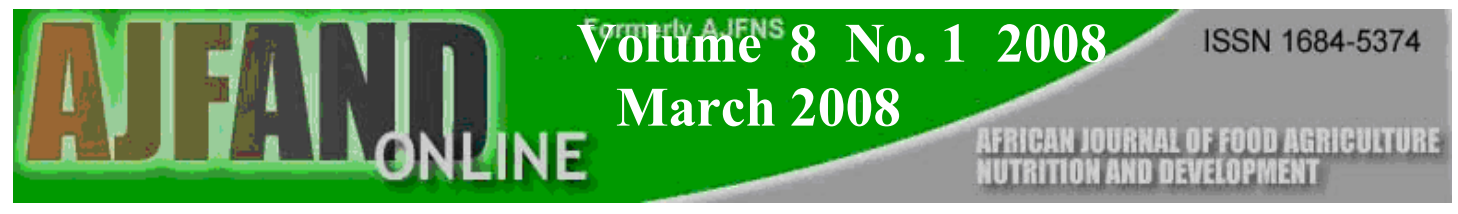

\title{
ENHANCING NUTRITIONAL DENSITY AND QUALITY OF BANANA-SOY BASED COMPLEMENTARY DIET THROUGH SUBSTITUTION WITH SESAME
}

Bukusuba $\mathbf{J}^{1^{*}}$, Isabiry $\mathrm{F}^{1}$ and $\mathrm{P}$ Nampala ${ }^{1}$

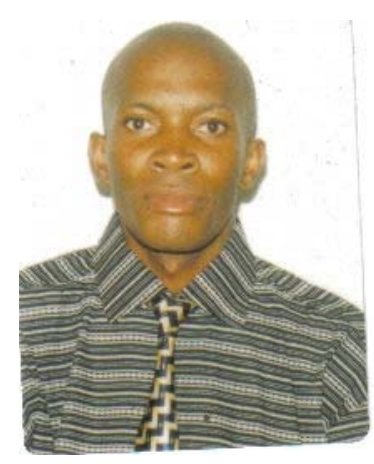

John Bukusuba

*Corresponding Author: Email: jbuk2001ug@yahoo.com

${ }^{1}$ John Bukusuba, Florence Isabirye and Paul Nampala. Department of Food Science and Technology, Makerere University, P.O Box 7062 Kampala, Uganda, 


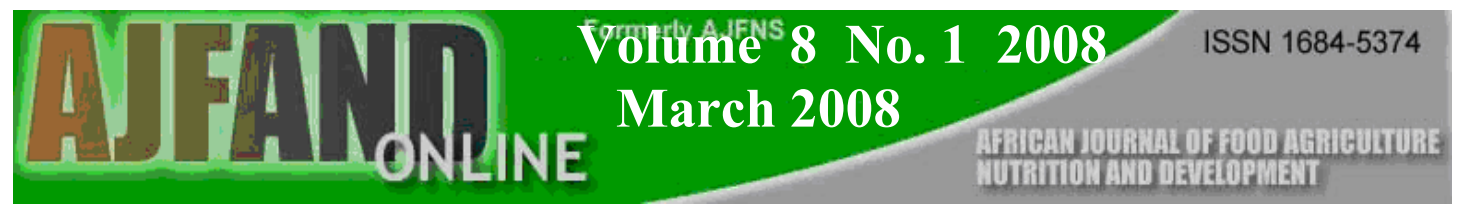

\begin{abstract}
Although Uganda is well endowed with adequate food supplies, more than one third of the children under the age of five are malnourished and $60 \%$ of all deaths of children under five years of age are directly or indirectly attributable to malnutrition. The causes of this public health problem in Uganda are complex and multidisciplinary, but poor quality and quantity of foods given to children play a major role. In this study, we conducted a rat feeding trial experiment in order to explore the potential of a banana-soy based diet optimally incorporated with sesame as a complementary diet to support growth of children. The study applied sensory evaluation and rat feeding trial experiments to investigate the optimum level of sesame incorporation in an earlier formulated bananasoy diet and as well explore the nutritional value of the final diet. Crude protein, ash and energy contents of the formulations were determined using AOAC methods. Data were analyzed using GenStat 5 Release 3.2. Nutrient and energy composition was compared using ANOVA and PER was compared using t-test. Results showed that a mixture of $67 \%$ banana, $16.5 \%$ soybean and $16.5 \%$ sesame flours produced a blend whose proximate analysis, PER and sensory evaluation studies had satisfactory nutritional quality, quantity and optimum organoleptic attributes. There was a high nutritional quality attained when soy and sesame flours were mixed in equal proportions. Therefore optimum incorporation of soybean and sesame in banana based complementary diets not only greatly enhances nutrient density and quality of these diets but also their organoleptic attributes. Feeding children these diets could break the cycle of childhood malnutrition through reduced feeding of starchy gruels that have low energy and protein contents or with undesirable sensory properties. The mixture is also easy to prepare at community level and may be adequate for catch up growth among children recovering from malnutrition.
\end{abstract}

Key words: Malnutrition, Nutrient Density, Optimization, complementary 


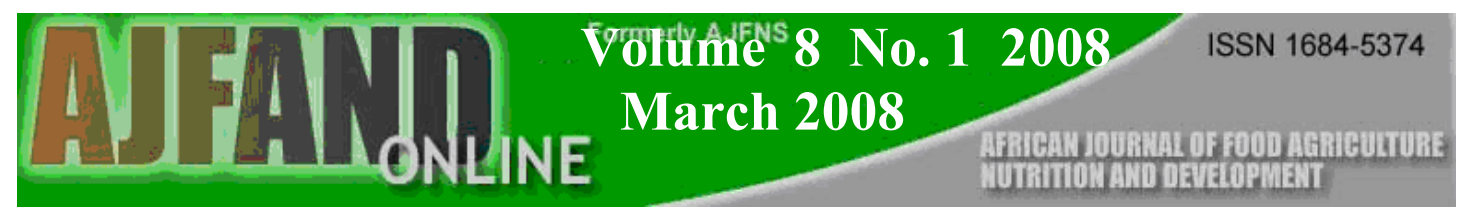

\section{INTRODUCTION}

It is now apparent that undernutrition of infants and young children in developing countries may result, in part, from inadequate energy and nutrient intake $[1,2,3]$. The possible causes of insufficient energy and nutrient consumption include; limited household food availability, inadequate frequency of feedings, poor psychosocial interaction between the caregiver and the child, depressed appetite of the child due to illness, and specific dietary factors [1-5]. Among the dietary contributory factors, inadequate energy and nutrient density, high viscosity or undesirable sensory properties of the diet have been highlighted $[1-3,6]$.

Although Uganda is well endowed with adequate food supplies, a large proportion of children under five years of age are malnourished and $60 \%$ of all deaths of these children are directly or indirectly attributable to malnutrition [7]. Findings from the Uganda Demographic and Health Survey [8] showed that 39\% of children under five years of age are chronically malnourished (stunted), which is almost 20 times the level expected in a healthy, well-nourished population [8,9]. Acute malnutrition, manifested by wasting, affects $4 \%$ of the children, which is twice the level expected in a healthy population. Twenty-three percent $(23 \%)$ of children under five years of age are underweight for their age. This is more than 11 times the level expected in a healthy, well-nourished population $[8,9]$.

It was reported that although the causes of malnutrition are complex and multidisciplinary, dietary factors do play a major role $[6,7,10]$. Poor dietary practices can lead to stunted growth, delayed motor and mental development, immune incompetence, frequent attacks of diarrhoeal disease, macro- and micronutrient deficiencies and most importantly, interference with the realization of full human potential [11]. Kikafunda et al. [7] found that children who were fed foods of low energy density (kcal/100g dry matter) had greater incidence of stunting. A related study among children in Kenya, aged 12-36 months, found that early complementation with starchy gruels was associated with stunting [12]. In this study, we applied sensory evaluation and a feeding trial experiment using laboratory rats to explore the potential of an earlier developed banana-soy based diet as a complementary diet for children, but optimally incorporating soybean and sesame flours.

\section{MATERIALS AND METHODS}

\section{Preparation of flours}

Flour preparations were done at Makerere University Department of Food Science and Technology laboratory in Kampala, Uganda. Pre-gelatinized banana flour was produced using a method by Muranga and Haase [13] but with modification to suit the traditional banana cooking process of "matooke.". Bananas were washed and cooked in a pressure 


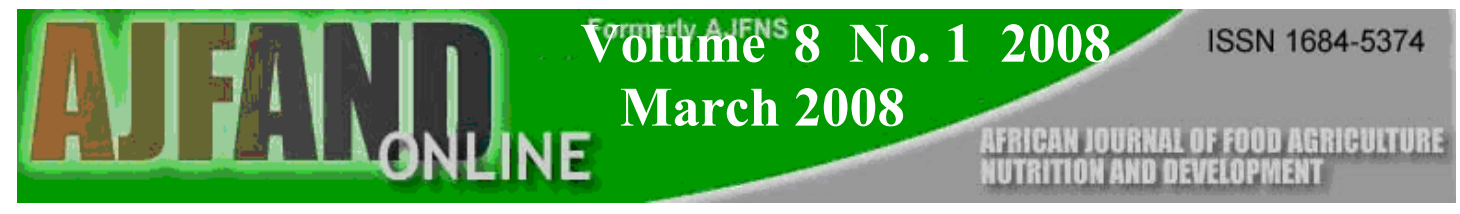

cooker at a temperature ranging between $98-100^{\circ} \mathrm{C}$ for five minutes until tender. This time was adequate to sufficiently loosen the banana peel, allowing hand stripping off of the peels. After cooling the banana fingers under tap water $\left(23^{\circ} \mathrm{C}\right)$, the peels were removed and sliced into half an inch slices. The slices were arranged on trays and dried in an oven at $60^{\circ} \mathrm{C}$ for about 12 hours.

Dry soybeans (Glycine max) were dehulled and extruded using the single screw extruder to obtain extruded soybean flour. Sesame seeds (Sesame indicum) were soaked in hot $0.6 \%$ sodium hydroxide for one minute, then washed with excess tap water at $23{ }^{\circ} \mathrm{C}$, scrubbed to remove the hull and dried in a hot air oven (Size 2, SG93/B6/95 Gallenkamp, $\mathrm{UK})$ at $60^{\circ} \mathrm{C}$ for 12 hours. The dry dehulled seeds were roasted in an oven at $170^{\circ} \mathrm{C}$ for 25 minutes, and then pounded to obtain processed sesame flour.

\section{Determination of optimum level of soybean and sesame incorporation}

The recommendation of three parts to one part (starchy base:soy) was adapted for this experiment $[14,15]$. The experiment was therefore based on the 3:1 ratio of starchy flour to protein rich flour. The sensory evaluation experiment allowed comparison of the optimum levels of sesame replacement (50\% substitution of soy with sesame) against test porridges made from maximum level of soy and sesame substitution (33\%) in the respective banana flours (Table 1$)$.

The optimum level of incorporation of sesame (Se) in banana-soy (BaSo) flour was established with respect to key sensory indicator parameters using a test porridge prepared by dissolving $35 \mathrm{~g}$ of banana-soy based flour (Table 1) in $100 \mathrm{ml}$ of cold water, then added to $300 \mathrm{ml}$ of boiling water and boiled for seven minutes with stirring. To each porridge, $10 \mathrm{~g}$ of sugar were added and evaluated by a panel of 15-trained members according to colour, flavor, taste and texture using a 9-point hedonic scale $(1=$ like extremely to 9 = dislike extremely). Further experiments were based on the sensory evaluation results. Panelists reported poor acceptability scores for BaSo and BaSe based porridges. This was attributed to the unpleasant cooked flavor of soybean and the astringent taste of sesame when in high quantities $[15,16]$.

\section{Proximate analysis}

Moisture, crude protein, ash and energy contents of the flours and formulations were determined using standard AOAC methods [17,18]. Moisture content of the samples was determined by oven drying for two hours at $135^{\circ} \mathrm{C}$ (AOAC: 930.15). Approximately $2 \mathrm{~g}$ of the ground sample was weighed using an analytical electronic balance, accurate to 0.1 $\mathrm{mg}$ and added to each dried aluminum dish. After moisture was evaporated from the samples, they were placed in a desiccator to cool. The percentage of the average difference in weights of three samples of each flour, before and after oven drying was calculated as moisture content. 


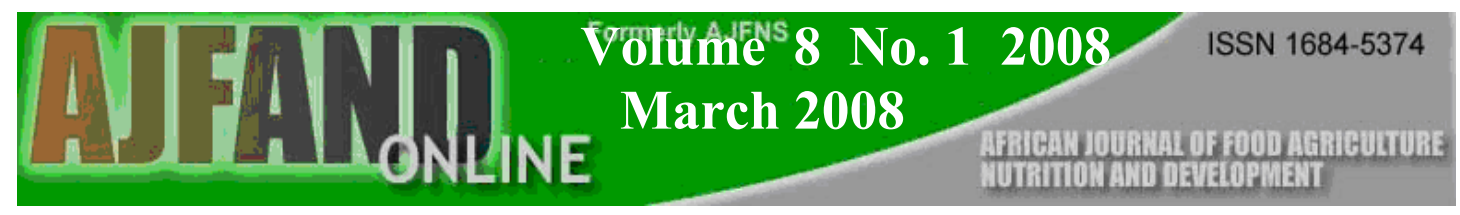

Crude Protein content of the samples was determined using the Kjeldahl method (AOAC 984.13). The method consists of three basic steps: i) digestion of the sample in sulfuric acid with a catalyst, which results in conversion of nitrogen to ammonia; ii) distillation of the ammonia into a trapping solution; and iii) quantification of the ammonia by titration with a standard solution. According to this method, $\%$ crude protein content of a sample $=\%$ nitrogen $\times 6.25$.

To determine Ash content, a dried and ground sample was ignited in a furnace at $600^{\circ} \mathrm{C}$ for 2 hours to oxidize all organic matter. Crucibles were first dried for about 2 hours at $100^{\circ} \mathrm{C}$ in an oven and placed in a desiccator. They were cooled and their weights recorded to the nearest $0.1 \mathrm{mg}$. About $2.0 \mathrm{~g}$ of sample was weighed into the crucible, recording weight of crucible with cover and sample to the nearest $0.1 \mathrm{mg}$. The samples were then placed in a furnace at $600^{\circ} \mathrm{C}$ for two hours. Percentage ash content was determined by weighing the resulting inorganic residue. Gross energy content of the samples was determined using bomb calorimeter method [17].

The Protein Efficiency Ratio (PER) was calculated as follows;

$$
P E R=\frac{\text { Weight gain of test animal }}{\text { protein } \text { consumed }}
$$

Corrected PER $=$ PER $X \frac{2.5}{\text { PER for control (casein) }}$

\section{Feeding trials}

The feeding trials were done at Makerere University, Faculty of Veterinary Medicine and were conducted using laboratory rats at weaning stage (20-23 days of age). The relative growth rates (as weight gains) were measured for rats fed the (i) optimal sesame substituted diet (BaSoSe; 67:16.5:16.5), (ii) pre-gelatinized banana-soy diet (BaSo; 67:33). Since undesirable sensory properties of the diet have been highlighted as one of the contributory factors to insufficient energy and nutrient intake among under fives, we did not proceed with the feeding trial experiment of the BaSe diet. Panelists gave very low color and flavor scores for this formulation. BaSo, however, received a fair score in terms of color and flavor, thus the feeding trial experiment compared these formulations (BaSoSe and BaSo), and (iii) standard diet prepared from powdered milk partially substituted with starch to obtain a basal ration with casein at the level of $10 \%$ protein [19]. The formulated diets were fortified with $2.5 \mathrm{~g}$ of mineral premix and $2.5 \mathrm{~g}$ vitamin premix per kg. Each diet was fed to a cluster of seven weanling rats in individual cages 


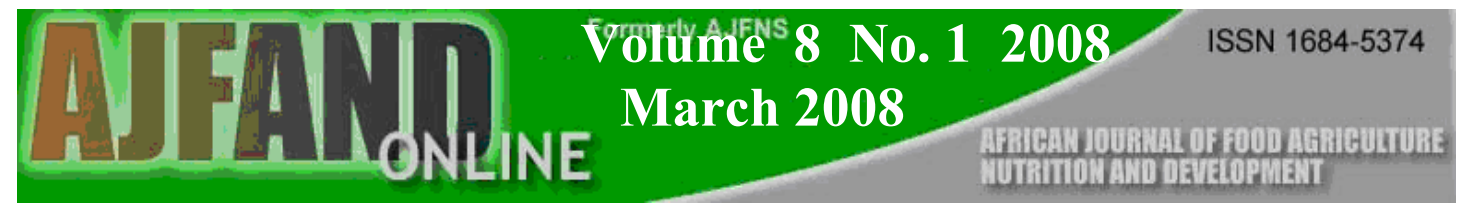

provided with feeders and water containers. The diets and water were supplied ad libitum.

\section{Data analysis}

Data were analyzed using GenStat 5 Release 3.2. Nutrient and energy composition of the flours was compared using Analysis of Variance (ANOVA) and means were separated by Least Significant Difference (LSD) test. PER data were compared using t-test and for all statistical tests, $\mathrm{P}<0.05$ was considered significant.

\section{RESULTS}

Based on the comments from the panelists, BaSoSe based porridge was found to be the most acceptable (Table 1). BaSoSe porridge received the best hedonic scores $(2=$ like very much) where as BaSo and BaSe porridges were considered the least acceptable $(4=$ like slightly). These sentiments expressed were similar to earlier sensory evaluation studies where poor acceptability of BaSo and BaSe based porridge was attributed to the unpleasant cooked flavor of soybean and the astringent taste of sesame when in high quantities $[15,16]$. From the general remarks of the panelists, it was evident that the high quantities of sesame in BaSe and soybean in BaSo made the ultimate porridges less acceptable because of their poor colour and unpleasant flavour. Feeding trials to assess the capacity of banana based diets to support growth were therefore done using the BaSoSe formulations comparing it with the earlier developed formulation (BaSo) and a control diet.

The crude protein, ash and energy content of the formulations are shown in Table 2. Substitution of soy and sesame flours in banana based formulations significantly increased the crude protein and ash contents (Table 2). The high reported protein $(36.97 \%)$ and ash $(5.80 \%)$ contents of soybean possibly resulted in subsequent higher contents of these nutrients in the banana-soy based formulations. Although formulations had significantly different protein contents, the differences in energy content were not as noticeable.

The control had the least protein content and yet it gave the best weight gains. Similarly though BaSoSe had less crude protein content than BaSo, it gave better weight gains than BaSo formulation. Experimental rats fed on the control diet exhibited the highest average PER value (2.5), an indicator of high quality of this diet (Table 3). The average corrected PER value of rats fed on BaSoSe diet (1.72) at the end of the experimental period was higher than that of BaSo (0.86), possibly signifying the higher nutritional quality of the former diet. All experimental rats responded positively to the formulations as seen in terms of weight gain (Figure 1). The average weight gain of rats consuming BaSoSe diet per week was significantly more than that of the BaSo diet $(\mathrm{P}<0.001)$. 

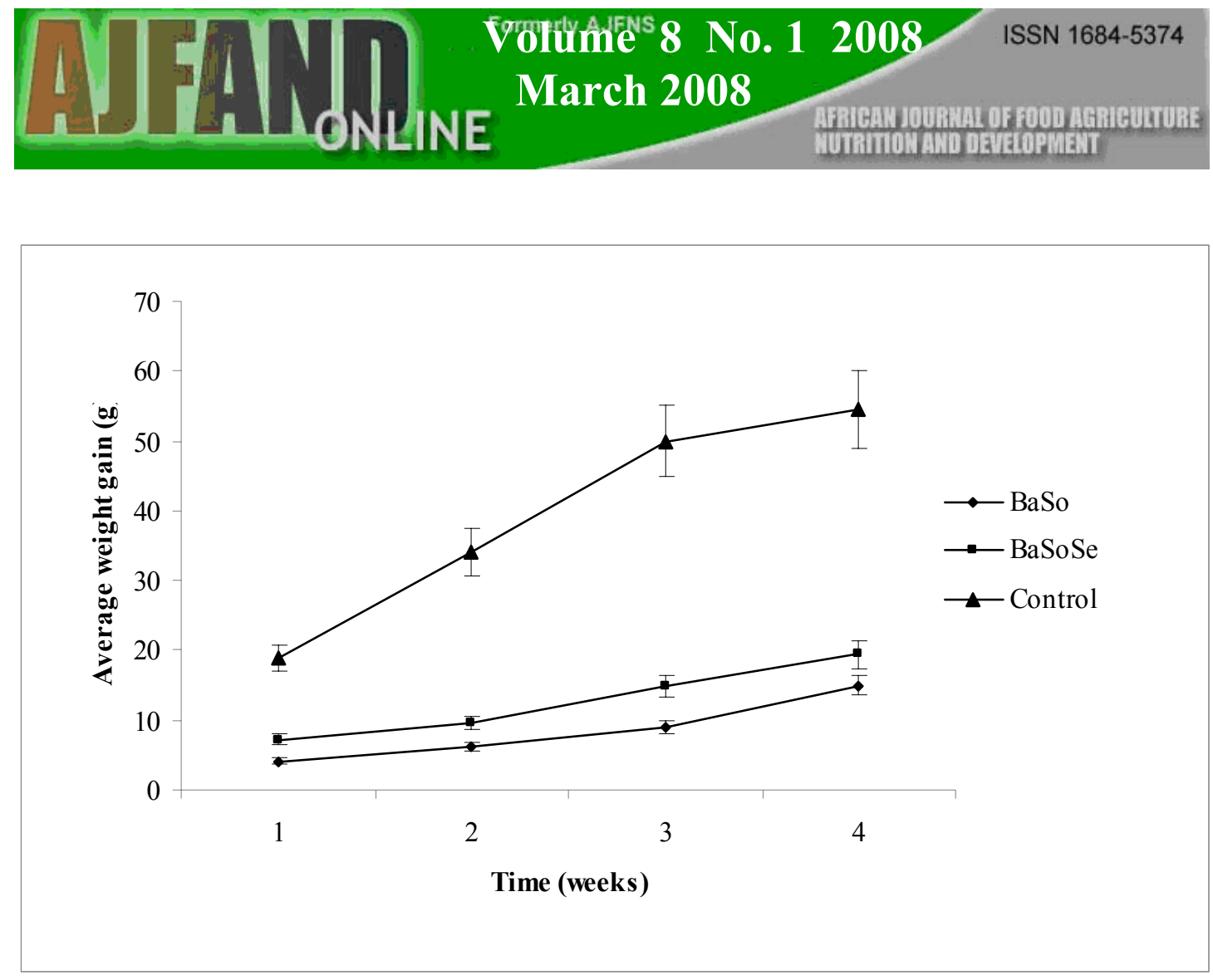

Figure 1: Graph showing weekly change in weight of rats fed experimental diets

\section{DISCUSSION}

Childhood malnutrition is a significant public health problem in Uganda, affecting more than one third of the children under the age of five [20]. Low quality of complementary foods, poor child-feeding practices, and high rates of infections have been reported as major contributory factors to poor health and growth in this vulnerable group $[6,7,20,21,22]$. A study in Uganda revealed that while breast-feeding was universal at birth, early weaning with watery, energy and nutrient poor staples was widespread in rural area [22]. It was noted that complementary foods were dominated by the green cooking banana ("matooke") which is known to be bulky with low nutrient content, a possible risk factor for the high levels of malnutrition among children under five years in Uganda.

Other earlier studies on dietary causes of malnutrition showed that "matooke", cassava and other root tubers, which are fed during the weaning period, are low in both energy and protein densities because they tend to be bulky [7,14]. The accompanying bean, groundnut sauce, meat or fish is not normally adequate to compensate for the low energy and protein in the staple. This suggests the need for processing and substitutions aimed at enhancing the nutritional value of cooking banana to meet the nutritional requirements of 
children. Results of the proximate analysis showed that all formulations had adequate protein and energy contents to meet the recommendations in children $[23,24,25]$.

Sensory evaluation by panelists revealed that when sesame flour is substituted in a banana:soy formulation (67:33), optimum acceptability is obtained when soy and sesame flours are combined in equal proportions each at $16.5 \%$ of the final formulation. Salunkhe et al. [16] reported that protein foods suitable for feeding infants have been successfully produced from a mixture of groundnut, soy and sesame flours in a ratio of $4: 4: 3$. It was noted that defatted sesame meal could be used up to $18 \%$ level with out any detrimental effect on the sensory attributes of salami. Substitution of a locally consumed stable food (cooking banana) in the above formulation as in the current experiment therefore makes a suitable infant diet.

The fact that BaSoSe diet contains less protein (13.17\%) than BaSo (14.24\%) and yet the rats fed on the former diet exhibited higher growth results, reveals the fact that the nutritional value of BaSoSe is possibly better. The control diet though contained the least protein content from the proximate analysis experiment $(10.20 \%)$, yet it had the highest PER value possibly because of its high protein quality as well compared to BaSo and BaSoSe (Table 3). Studies elsewhere showed that incorporation of sesame in black bean meal significantly improved the protein quality, particularly methionine content and resulted in higher PER values [16,26]. It was noted that maximum PER was obtained when sesame and black bean flours were mixed in 1:1 proportion [16]. Similarly, the PER was higher for the BaSoSe in contrast to BaSo formulation, probably because of the better amino acid profile in BaSoSe formulation. This shows that BaSo was inferior in nutritional quality to BaSoSe diet. The feeding trial experiment therefore showed that weight gain possibly varied with the quality of protein in the diet. Though the protein quality of casein could not be matched by either BaSo or BaSoSe formulations, BaSoSe was found to be superior to BaSo diet thereby indicating that optimum incorporation of sesame and soybean exerts beneficial effect with respect to growth possibly through improvement of protein quality.

According to FAO [27], the main nutrient supplied by cooking bananas is dietary energy provided by carbohydrates. The protein content is low and sulphur-containing amino acids are the most limiting amino acids. Sesame has been reported as one of the locally grown crops that is rich in sulphur-containing amino acids, particularly methionine [16]. The results of this experimental study to enhance nutritional density and quality of a starch based diet are similar to findings on studies of PER among other starch staples reported by Dewey \& Brown [25], FAO [27], Malleshi et al. [28] and Geervani et al. [29]. The results of this study demonstrated that the biological value or nutrient quality of banana based complementary diet can be increased by the addition of soybean and sesame. Several studies also noted that legumes complement each other so that the nutritional value of the mixture is greater than that of either ingredient 
$[14,16,28,30,31,32]$. Salunkhe et al. [16] further reported that supplementation of sesame flour with $1.25 \%$ lysine improved the nutritive value of proteins making them comparable to that of skim milk powder. In another study the diet containing decorticated sesame seed showed growth performance and food efficiency ratio comparable to that of casein (control) diet demonstrating the high quality of sesame protein [23].

Sesame and soybean incorporated in cooking banana in varying proportions to determine the blend that would give the required sensory attributes and protein density and quality in baby foods confirmed an optimistic benefit stipulated in other studies [15,16,33]. Therefore, optimum incorporation of soybean and sesame in banana based diets improves the nutritional value and organoleptic properties to that which is of significance in complementary diets for children. These findings could address questions on what to wean with, a subject of great importance in Uganda which has not received adequate scientific attention.

\section{CONCLUSION}

From the results of the experiment, sesame optimally incorporated in banana-soy flour at $16.5 \%$ significantly increased energy content and overall acceptability of the final diet. The substitution possibly enhanced protein quality as well, as seen from the feeding trial experiment. This experiment can be extended to feeding trials in children and given that malnutrition is among the major nutrition problems among Ugandan children, such nutritionally balanced diets from BaSoSe would help to mitigate the problem. This will help break the cycle of childhood malnutrition through reduced feeding of starchy gruels that have low energy and protein contents or with undesirable sensory properties. The mixture is as well very easy to prepare at community level and may be adequate as well for catch up growth among children recovering from malnutrition. Subsequent related studies need to explore the intake and acceptability trials of banana-soy-sesame diet among children under five years of age particularly those suffering from grade I and II malnutrition. Studies of amino acid profiles of the formulated soy and sesame based diets could as well explain the protein quality of these diets.

\section{ACKNOWLEDGEMENT}

We gratefully acknowledge the co-operation and assistance of the staff of Department of Food Science \& Technology, Department of Animal Science and Faculty of Veterinary Medicine at Makerere University in Uganda that made this study successful. We also thank the Rockefeller Foundation through ACA project for funding the study. 


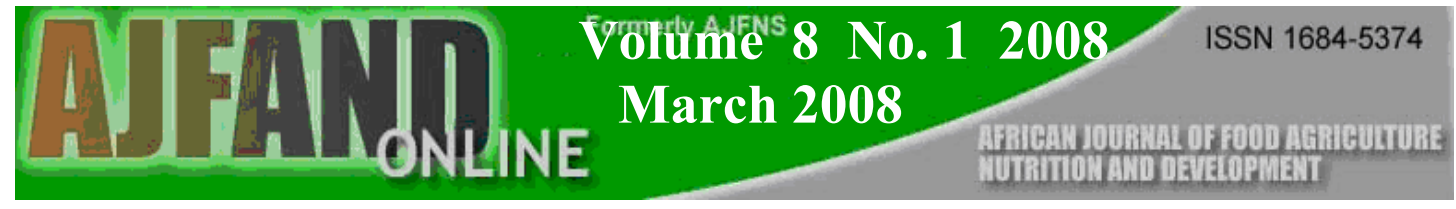

Table 1: Levels of sesame incorporation in banana-soy formulation for optimization

\begin{tabular}{lccc}
\hline & \multicolumn{3}{c}{$\%$} \\
\cline { 2 - 4 } Code & Banana (Ba) & Soybean (So) & Sesame (Se) \\
\hline BaSo & 67 & 33 & 0 \\
BaSoSe & 67 & 24.75 & 8.25 \\
BaSoSe & $\mathbf{6 7}$ & $\mathbf{1 6 . 5}$ & $\mathbf{1 6 . 5}$ \\
BaSoSe & 67 & 8.25 & 24.75 \\
BaSe & 67 & 0 & 33 \\
\hline
\end{tabular}

Table 2: Nutrient and energy contents of formulations

\begin{tabular}{lccc}
\hline \multirow{2}{*}{ Formulation } & \multicolumn{3}{c}{ Composition } \\
\cline { 2 - 4 } & Crude protein (\%) & Total ash (\%) & Gross Energy (Kcal/g) \\
\hline Control & $10.20 \mathrm{~b}$ & $5.53 \mathrm{f}$ & $5.57 \mathrm{~b}$ \\
BaSo & $14.24 \mathrm{e}$ & $5.27 \mathrm{e}$ & $4.25 \mathrm{a}$ \\
BaSoSe & $13.17 \mathrm{~d}$ & $4.09 \mathrm{c}$ & $4.59 \mathrm{a}$ \\
BaSe & $10.64 \mathrm{c}$ & $3.70 \mathrm{~b}$ & $4.99 \mathrm{a}$ \\
Extruded soybean & $36.97 \mathrm{~g}$ & $5.80 \mathrm{~g}$ & $5.22 \mathrm{~b}$ \\
Processed sesame & $20.80 \mathrm{f}$ & $4.40 \mathrm{~d}$ & $7.40 \mathrm{c}$ \\
Dried banana & $4.08 \mathrm{a}$ & $3.37 \mathrm{a}$ & $3.66 \mathrm{a}$ \\
\hline LSD $(\mathrm{P}<0.001)$ & 0.05 & 0.01 & 1.19
\end{tabular}

Means within a column with the same letter are not significantly different $(\mathrm{P}<0.05)$








Table 3: PER for the three experimental formulations

\begin{tabular}{lcc}
\hline Formulation & PER & Corrected PER $^{*}$ \\
\hline Control & 2.11 & 2.50 \\
BaSo & 0.73 & 0.86 \\
BaSoSe & 1.43 & 1.72 \\
\hline
\end{tabular}

*Corrected PER significantly different $(\mathrm{P}<0.001)$ 


\section{REFERENCES}

1. Treche $\mathbf{S}$ The effect of energy density and viscosity of porridges on the energy intake of infants. Sante, 1996; 6: 237-243.

2. Bennett VA, Morales E, Gonzalez J, Peerson JM, Lopez de Romana G and KH Brown Effects of dietary viscosity and energy density on total daily energy consumption by young Peruvian children. Am J Clin Nutr. 1999; 70: 285-291.

3. Yamashiro Y Overview of Complementary Feeding (Weaning) in Countries of Asia. J Pediatr. 2000; 106: 1274.

4. Bukusuba J, Kikafunda JK and RG Whitehead Food security status in households of people living with HIV/AIDS (PLWHA) in a Ugandan urban setting. Br J Nutr. 2007; 98: 211-217.

5. Appoh LY and S Krekling Maternal nutritional knowledge and child nutritional status in the Volta region of Ghana. (C) Blackwell Publishing Ltd, Maternal and child nutrition. 2005; 1: 100-110.

6. Arimond M and MT Ruel. Dietary Diversity, Dietary Quality, and Child Nutritional Status: Evidence from Eleven Demographic and Health Surveys. FANTA, Washington, DC. 2004; 1-5.

7. Kikafunda JK, Walker AF, Collett D and JK Tumwine Risk Factors for Early Childhood Malnutrition in Uganda. J Pediatr. 1998; 102: 45-53.

8. Uganda Demographic Health Survey (UDHS). Uganda Bureau of Statistics, Entebbe, Uganda and ORC Macro Calverton, Maryland, USA. 2000/2001: 154, 155.

9. Uganda Bureau of Statistics (UBOS), Macro ORC and USAID. Nutrition of Young Children and Mothers in Uganda African Nutrition Chart books, ORC macro, Calverton, Maryland, USA. 2001; 1-74.

10. Tumwine JK and $\mathbf{W}$ Barugahare. Nutrition status of children in Kasese district at the Uganda-Congo border. East Afr Med J. 2002; 79: 427-34.

11. Kruger R and GJ Gericke A qualitative exploration of rural feeding and weaning practices, knowledge and attitudes on nutrition. Public Health Nutr. 2003; 6: 217223. 
12. Onyango A, Koski KG and KL Tucker Food diversity versus breastfeeding choice in determining anthropometric status in rural Kenyan toddlers. Int J Epidemiol. 1998; 27: 484-489.

13. Muranga FI and NU Haase Characteristics of dried matooke flours, 1997. Unpublished..

14. Muranga FI Incorporation of soybean into local diets. Proceedings of the first workshop on soybean production and utilization held at Mukono District farm Institute on $2^{\text {nd }}-6^{\text {th }}$ March. 1992.

15. Ogazi PO, Oyewusi FA, Ozumba AU, Ogundipe HO, Osifo BOA and FA Lukambi Development and sensory evaluation of soyamusa: a soybean-plantain baby food. International Conference on Banana and Plantain for Africa, 2001; 1.

16. Salunkhe DK, Chavan JK, Adsule RN and SS Kada. World oil seeds; Chemistry, Technology and Utilisation. Van Nostrand Reinhold New York. 1992; 11-40, 373394.

17. AOAC.Official Methods of Analysis, $16^{\text {th }}$ Edition AOAC International. Gaithersberg, Maryland, USA. 1997.

18. Undersander $\mathbf{D}$, Mertens DR, and $\mathbf{N}$ Thiex Forage analyses procedures. Collaboration of University of Wisconsin, USDA-ARS US Dairy Forage Research Center and National Forage Testing Association. 1993; 14-15, 48-52.

19. Gopaldas $\mathbf{T}$ Malted versus roasted weaning mixes: development, storage, acceptability, and growth trials. (C) The United Nations University, 1984. Proceedings of a workshop held at Hyderabad, India, 10-12 November 1981.

20. Uganda Bureau of Statistics (UBOS), Macro ORC and USAID. Nutrition of Young Children and Mothers in Uganda African Nutrition Chart books, ORC macro, Calverton, Maryland, USA. 2001; 1-74.

21. Sewanyana SN Food security and child nutrition status among urban poor households in Uganda: Implications for poverty alleviation. AERC Research Paper 130, African Economic Research Consortium, Nairobi. (C) 2003, African Economic Research Consortium. 2003; 2, 3, 6, 54-57.

22. Kikafunda JK, Walker AF and JK Tumwine Weaning Foods and Practices in Central Uganda: A Cross-Sectional Study. Afri. J. Food. Ntri. Sci. 2003; 3 . 
23. Gibson RS, Ferguson EL and $\mathbf{J}$ Lehrfeld Complementary foods for infant feeding in developing countries: their nutrient adequacy and improvement. Eur J Clin Nutr. 1998; 52: 764-770.

24. Brown KH WHO/UNICEF Review on Complementary Feeding and Suggestions for Future Research: WHO/UNICEF Guidelines on Complementary Feeding. J Pediatr. 2000; 106: 1290.

25. Dewey KG and KH Brown Update on technical issues concerning complementary feeding of young children in developing countries and implications for intervention programs. Food Nutr Bull. 2003; 24: 239.

26. Sen M and DK Bhattacharyya Nutritional quality of sesame seed protein fraction extracted with isopropanol. J Agric Food Chem. 2001; 49: 2641-2646.

27. FAO. Roots, Tubers, Plantains and Bananas in human nutrition. FAO food and nutrition series, Rome. 1990; 10, 21, 41, 102.

28. Malleshi NG, Hadimani NA, Chinnaswamy R and CF Klopfenstein. Physical and nutritional qualities of extruded weaning foods containing sorghum, pearl millet, or finger millet blended with mung beans and nonfat dried milk. Plant Foods Hum Nutr. 1996; 49: 181-189.

29. Geervani P, Vimala V, Pradeep KU and MR Devi Effect of processing on protein digestibility, biological value and net protein utilization of millet and legume based infant mixes and biscuits. Plant Foods Hum Nutr. 1996; 49: 221-227.

30. Tchango $\mathbf{J}$ The nutritive quality of maize-soybean (70:30) tempe flour. Plant Foods Hum Nutr. 1995; 47: 319-26.

31. Jeejeebhoy KN Vegetable proteins: are they nutritionally equivalent to animal protein. Eur J Gastroenterol Hepatol. 2000; 12: 1-2.

32. Mosha TC and MM Vicent Nutritional value and acceptability of homemade maize/sorghum-based weaning mixtures supplemented with rojo bean flour, ground sardines and peanut paste. Int J Food Sci Nutr. 2004; 55: 301-315

33. Lusas EW and MN Riaz Soy protein products: processing and use. J Nutr. 1995; 125: 573-580. 